Referencia para citar este artículo: Meza-Maya, C. V. \& Lobo-Ojeda, S. M. (2017). Formación en valores sociales en adolescentes que juegan Grand Theft Auto V. Revista Latinoamericana de Ciencias Sociales, Niñez y Juventud, 15 (2), pp. 1051-1065. DOI:10.11600/1692715x.1521726012017

\title{
Formación en valores sociales en adolescentes que juegan Grand Theft Auto V*
}

\author{
Clara Victoria MeZa-MaYA** \\ Profesora-investigadora, Universidad Santo Tomás, Colombia. \\ SANDRA MARCELA LOBO-OJEDA*** \\ Profesora-investigadora, Universidad Santo Tomás, Colombia.
}

\section{Artículo recibido en enero 26 de 2017; artículo aceptado en marzo 3 de 2017 (Eds.)}

- Resumen (analítico): Objeto: comprensión de las relaciones entre los preadolescentes y las nuevas prácticas comunicativas en las redes informáticas, respecto a la construcción de valores sociales que se propician mediante su participación en los videojuegos colaborativos, en una observación en adolescentes con el videojuego Grand Theft Auto V (GTA V). Metodología: es un estudio cualitativo, con herramientas etnográficas, apoyado por una encuesta tipo Likert, con estudiantes de un colegio de Bogotá. Resultados y conclusiones: Los estudiantes diferencian con claridad el contexto valorativo del juego y el de la vida real. Los valores sociales como el respeto, la solidaridad, la otredad y el cumplimiento de las normas tienen significaciones diferentes en el juego y en la vida. La familia es la fuente de valores más reconocida en la vida real. Se extraen enseñanzas del mundo avieso del juego.

Palabras clave: valores sociales, preadolescentes, comunicación interactiva, ética, videojuego (Tesauro de Ciencias Sociales de la Unesco).

Palabras clave autoras: espacios convergentes, videojuegos colaborativos, Grand Theft Auto V.

\section{Formation of social values in adolescents that play Grand Theft Auto V}

- Abstract (analytical): Objective: To understand the relationships between pre-adolescents and new communicative practices in computer networks in terms of the construction of social values that are fostered through their participation in collaborative video games by observing adolescents playing the Grand Theft Auto V (GTA V) video game. Methodology: This is a qualitative study that used ethnographic tools supported by a Likert type survey with students from a school in Bogotá. Results and conclusions: Students clearly differentiate between the values context of the game and values in real life. Social values such as respect, solidarity, otherness and compliance have different

Este artículo de investigación científica y tecnológica presenta los resultados de la investigación titulada "Análisis del videojuego Grand Theft Auto V y la formación en valores sociales en estudiantes de séptimo grado del Colegio Santo Tomás de Aquino", realizada entre el 16 de febrero y el 20 de noviembre de 2015, favorecida en la Novena Convocatoria Interna de Proyectos de Investigación-Fodein 2014, de la Universidad Santo Tomás, Bogotá. Código del proyecto SIGP/Código entidad financiadora 6110022003. Se trata de un estudio etnográfico con entrevistas y encuesta. El tema se inscribe en el área grande de las ciencias de la comunicación social, y se relaciona con las áreas comunicación y mediaciones, análisis de contenido, semiótica y pragmática, comunicología; y las sub-áreas periodismo, medios de comunicación, comunicación y educación, Información y comunicación (tic) y entretenimiento. En nuestro estudio, la comunicación se relaciona, además, de manera interdisciplinaria con la educación y la ética.

** Docente-investigadora, Universidad Santo Tomás. Comunicadora social-periodista; especialista en Comunicación-Educación y magister en Investigación en Problemas Sociales Contemporáneos. Orcid 0000-0002-6033-6492. Correo electrónico: clarameza@usantotomas.edu.co

**** Docente-investigadora, Universidad Santo Tomás. Comunicadora social-periodista, magíster en Ciencias de la Información y magíster en Educación. Orcid 0000-0003-4837-4207. Correo electrónico: sandralobo@usantotomas.edu.co

Rev.latinoam.cienc.soc.niñez juv 15 (2): 1051-1065, 2017 http://revistalatinoamericanaumanizales.cinde.org.co

DOI: $10.11600 / 1692715 \times .1521726012017$ 
meanings in the game compared to their lives. The family is the most recognized source of values for these students in real life while students gain learning experiences from the world of the game.

Key words: social values, pre-adolescents, interactive communication, ethics, video game (Unesco Social Sciences Thesaurus).

Authors' key words: convergent spaces; collaborative video games, Grand Theft Auto V.

\section{Formação de valores sociais em adolescentes que jogam Grand Theft Auto V}

- Resumo (analítico): Objeto: compreensão das relações entre os pré-adolescentes e novas práticas comunicativas em redes de computadores, em relação à construção de valores sociais que se propiciam através da participação em jogos colaborativos, a partir de uma observação em adolescentes com o vídeo game Grand Theft Auto V (GTA V). Metodologia: estudo qualitativo com ferramentas etnográficas, apoiado por uma entrevista de tipo Likert com estudantes de uma escola em Bogotá. Resultados e conclusões: Os alunos diferenciam claramente o contexto avaliativo do jogo e da vida real. Valores sociais como o respeito, a solidariedade, a alteridade e conformidade têm significados diferentes no jogo e na vida. A família é a fonte de valores mais reconhecida da vida real. Extraem-se ensinamentos do mundo destorcido do jogo.

Palavras-chave: valores sociais, pré-adolescentes, comunicação interativa, ética, videogames (Thesaurus de Ciências Sociais da Unesco).

Palavras-chave autoras: espaços convergentes, videojogos colaborativos, Grand Theft Auto V.

-1. Introducción. -1.1 Antecedentes teóricos del juego. -1.2. Estructura del juego. -1.3. El videojuego. -1.4. Aspectos estructurales del videojuego. -1.5. Los valores sociales y los videojuegos. -1.6. El Grand Theft Auto V. -2. Metodología. -3. Hallazgos. -3.1. Los grupos focales. -3.2. Entrevistas. -3.3. Triangulación a manera de conclusiones. -Lista de referencias.

\section{Introducción}

La investigación de la que proviene este texto indaga la relación entre los videojuegos colaborativos en redes sociales y la formación de valores sociales como tolerancia, respeto, solidaridad y reconocimiento de la alteridad en preadolescentes. El problema que se planteó se refiere al desacuerdo entre los investigadores que les otorgan a los videojuegos la capacidad de incentivar competencias cognitivas y de redes de relaciones, la capacidad de contextualizar y el incremento de las aptitudes de planeación, por un lado, y por otro lado los que consideran que los videojuegos, especialmente los de contenido violento, propician el aislamiento del niño o la niña, promueven la competencia, desestimulan la cooperación y son altamente adictivos. Para ubicarse en este debate, se trata aquí de comprender las relaciones entre los preadolescentes y las prácticas comunicativas en internet, respecto a la construcción de valores sociales propiciados por la participación en los videojuegos colaborativos. Como observa Victoria Camps (2002):

"la solidaridad, el respeto y un cierto altruismo son valores ausentes en un mundo marcado por la competitividad, la agresividad, y por un individualismo desde el cual todo lo que no sea el interés propio se convierte en una molestia que hay que eliminar" (p. 14).

Según algunas posiciones críticas respecto de las industrias lúdicas, son esos componentes de competencia, agresividad y aislamiento social la base de ciertas prácticas que contradicen la formación social en valores como la convivencia, el reconocimiento del débil y la solidaridad.

\subsection{Antecedentes teóricos del juego}

Johan Huizinga (1998) desarrolló una tesis sobre el significado del juego en la cultura, como una función humana junto a la reflexión $\mathrm{y}$ el trabajo. Es una función que no se agota en 
otras funciones psicológicas, emocionales o sociales.

La literatura sobre el juego se refiere especialmente a las teorías fisiológicas; la teoría sobre el exceso de energía, de Spencer; la teoría del ejercicio del juego preparatorio, de Gross; la teoría de la autoexpresión, de Manso y Mitchell; la teoría psicoanalítica; las teorías antropológicas y culturales, de Vygotsky; la teoría de la recapitulación de Hall, y la teoría cognitiva de Piaget.

- Teorías Fisiológicas. El juego es un fenómeno y una necesidad fisiológicos de los animales, los niños y las niñas y los adultos. El juego se desarrolla en la vida animal y humana como un fenómeno fisiológico. El animal y el niño o la niña, comienzan a jugar con ellos mismos, sin preparación, inician y terminan cuando quieren, establecen sus propias reglas y gozan el juego.

- Teoría sobre el exceso de energía. Algunos autores como Herbert Spencer (1969) en el siglo XIX, fundador de la teoría de la evolución en sociología, propuso la tesis de la descarga de energía a través del juego como una forma de liberación de la energía excedente. El ser humano juega hasta el cansancio, lo que permite liberar energía hasta el agotamiento.

- Teoría del juego preparatorio. A principios del siglo XX, Karl Gross (1902) entendió el juego como una preparación para el desarrollo de funciones centrales para cuando el niño o la niña sea adulto y como una autoafirmación preparatoria. El juego produce placer y hace olvidar la seriedad cotidiana. El juego es un medio un fin: "no jugamos porque somos niños, sino que se nos ha dado la niñez justamente para que podamos jugar" ( $p$. 68).

- Teoría de la autoexpresión. A mediados del siglo XX, Bernard Mason y Elmer Michel (1945), se interesaron por el valor del juego como un medio para manifestar la personalidad, una proyección de quienes quisieran ser a través del juego de roles.
- Teoría psicoanalítica. Sigmund Freud (1948) pensaba que el juego es una catarsis. Mientras se juega, se expresa placer por la recuperación de algo perdido, que es la madre que satisface, de modo que el principio del placer desaparece y se recupera en el juego. A través de las experiencias lúdicas el niño manifiesta sus deseos inconscientes y libera energía libidinal y angustia. Por su parte, Donald Winnicott (1982) considera que el juego ocurre en un área intermedia entre la subjetividad y la relación con el otro, de manera que es un "objeto transaccional", que provoca un proceso infantil que prepara funciones para la edad adulta.

- Teorías antropológicas, culturales y sociales. Lev Vygotsky (1978) formuló su teoría del desarrollo socio-históricocultural frente a otras teorías que se centran en el sujeto, y considera que el juego no nace del placer sino de las frustraciones del niño o la niña, determinadas por el contexto social, que cambia a través de situaciones ficticias, en las que el sujeto busca satisfacer sus deseos insatisfechos y plantea otras soluciones diferentes a las de la vida real. En esta misma línea se encuentra Huizinga (1998), quien sostiene que el juego nace en cada cultura como una forma de preservar los valores y transmitir ideologías.

- Teoría de la Recapitulación. Stanley Hall (1907) consideraba que el juego permite preservar la cultura. En su estudio de la adolescencia, Hall propone tres principios: 1. Los juegos corresponden a las etapas de desarrollo, definidas por el contenido de actividades lúdicas. 2. Los contenidos del juego se remiten a una cultura ancestral, y su aparición ha sido similar en todas las culturas. El animismo infantil, es similar al de los hombres primitivos. 3. El juego infantil tiene la función de superar las actitudes básicas de comer, dormir.

- Teoría Cognitiva. Piaget (1961) considera que el juego ayuda en la consolidación de las estructuras mentales, pues está relacionado con el desarrollo de las 
funciones cognitivas. El niño o la niña utiliza el juego y a su vez comienza a desarrollarse psíquicamente y las etapas por las que pasa su inteligencia se encuentran relacionadas con las etapas del juego.

\subsection{Estructura del juego}

Según Huizinga (1998), se pueden establecer constantes en la actividad lúdica, que permiten identificar el juego como una forma propia del desarrollo humano con algunas características:

- $\quad$ El juego es una actividad libre. La obligatoriedad anula el juego.

- El juego es un escape de la vida corriente, en el que se actúa «como sí...». Transcurre por sí mismo. Se juega solo en razón de la práctica lúdica.

- El juego tiene un límite espaciotemporal. El jugador tiene una memoria del juego más que por los resultados, por el hecho de haber jugado, que lo impulsa a volver a jugar después.

- El juego sigue un orden. Las acciones lúdicas siguen reglas que no se pueden transgredir porque se destruye el juego.

- $\quad$ El juego tiene un resultado incierto. Por eso, las reglas del juego son obligatorias, aunque el resultado sea abierto (Huizinga, 1998, pp. 34-35).

Estás características se extienden al videojuego actual, pues son la gracia y el encanto de jugar, en el juego se busca libertad, fantasía y emoción.

\subsection{El videojuego}

El videojuego es un poderoso medio de representación, entretenimiento y expresión. $\mathrm{Su}$ característica de medio digital abre un espacio para el análisis del videojuego como obra comunicativa (Pérez, 2011). Oliver Pérez define el videojuego como:

Un juego electrónico que cuenta como parte sustancial de su desarrollo con un dispositivo audiovisual, y donde generalmente un dispositivo de interfaz (teclado, mouse, gamepad) transfiere las acciones del jugador a la pantalla y las transforma o "traduce" en algún aspecto (p. 29).

El videojuego ofrece posibilidades que trascienden el juego tradicional por sus características electrónicas, audiovisuales y su dispositivo de interfaz. Le otorga al usuario la posibilidad de vivir una experiencia por medio de la interacción, que le permite la entrada al mundo virtual y representar un personaje. En los años setenta, aparecen los videojuegos como producto de la industria del entretenimiento y el desarrollo tecnológico. El pong (Atari), que aparece a principios de los años setenta fue el primer videojuego y originó uno de los más grandes inventos de la cultura del entretenimiento, que dejó de ser solo un objeto tecnológico y pasó a ser un objeto cultural en la sociedad del siglo XXI.

Los videojuegos inician con un modelo producto de la tecnología emergente, denominado "Social Gaming". Es un modelo de negocio de videojuegos que se instala sobre una plataforma de gestión de redes sociales personales tipo Facebook. A partir del 2007, diferentes empresas se han encargado del desarrollo de estos videojuegos, siendo las de mayor reconocimiento Zynga, Electronic Arts, Playdom, CrowStar, Social Point, Rock You.

Los videojuegos han existido antes y después de la aparición de la red, el plus de los juegos en red está en que los usuarios finales interactúen con el propio videojuego y con los otros usuarios en línea, ya que es clave tener "amigos" en una red social para apoyarse mutuamente en los diferentes retos que proponen. Este modelo se complementa con otro denominado Freemium; este videojuego ofrece servicios básicos en forma gratuita y a su vez otros servicios más avanzados (Premium) que tienen un costo adicional para el usuario final.

Los videojuegos en línea nos dan la posibilidad de interactuar con el otro y 
de esta manera ejercemos la dimensión humana de "ser social", característica que se vuelve un as bajo la manga, el trabajo en equipo para la resolución de tareas con un único objetivo: "ganar" (Meza-Maya, Lobo-Ojeda \& Uscátegui-Maldonado, 2014, p. 36).

\subsubsection{Videojuego y aprendizaje}

Como sucedió en el pasado con la televisión y con otros medios de comunicación, el videojuego es considerado como pasatiempo y no como una posible herramienta didáctica. Hay autores que sostienen que los videojuegos potencializan competencias cognitivas $y$ sociales. Este tema, sin embargo, merece una discusión detallada.

En todo videojuego, hay un discurso implícito, una visión del mundo y una valoración de los buenos y los malos, se asume de manera automática qué se debe hacer con ellos y se premian los aciertos y se castigan los errores. El problema consiste en saber si el videojugador aplica estas valoraciones en la vida fuera del videojuego.

De hecho, todo juego violento ha sido puesto bajo sospecha de ser causante de violencia social, lo que ha provocado el decomiso de pistolas de agua, espadas de plástico y otros juguetes por los padres preocupados por hacer de sus hijos "personas de bien". Se piensa que el juguete tiene una carga de violencia que se traslada de manera mecánica a la vida. En cambio, no se consideran algunas conductas de los padres, como la pela (limpia o paliza), el castigo o el premio, como provocadores de una conducta violenta. No se considera que la represión de la conducta por cualquier medio tenga también un discurso violento implícito que pueda incidir en la conducta de los hijos en la vida futura (y presente).

Entre quienes están a favor del videojuego como herramienta educativa (Revuelta \& Pedrera, 2012), por el uso de tecnologías para el aprendizaje (Aguilar, 2012), Ana María Sedeño sostiene que "Los videojuegos permiten introducir en el niño la reflexión sobre ciertos valores y conductas a través de su contenido y de las consecuencias de las acciones que efectúan virtualmente" (Sedeño, 2002, p. 1). Sedeño dice, además:

Por otro lado encontramos una dimensión educativa, que es la que se refiere a todo un ámbito de desarrollo de habilidades $y$ destrezas como son el control psicomotriz, la coordinación óculomanual, el desarrollo de la espacialidad y de la capacidad deductiva, la resolución de problemas, la imaginación, el pensamiento (la comprensión, la reflexión, la memorización, la facultad de análisis y síntesis) (Sedeño, 2002, p. 1).

En esta misma perspectiva, Provenzo (citado por Pérez, 2011) sostiene que:

Podemos interpretar los videojuegos como instrumentos clave de mediación entre el niño y su forma de entender la cultura que le rodea. En este contexto, videojuegos como los de Nintendo no son "neutrales" ni "inofensivos", sino que representan construcciones sociales y simbólicas muy específicas. En efecto estos videojuegos devienen poderosas máquinas pedagógicas, instrumentos de transmisión cultural (p. 32).

Queda claro, pues, que los videojuegos tienen potencialidades didácticas y ocultan también un discurso en su diseño, de modo que hay que distinguir entre el dispositivo tecnológico y la construcción del videojuego como dos factores que deben ser evaluados separadamente.

\subsection{Aspectos estructurales del videojuego}

El estudio del videojuego como discurso y el videojuego como lenguaje, según Oliver Pérez apunta a las estructuras lúdicas, narrativas $\mathrm{y}$ enunciativas en las que se fundamenta el videojuego y a la microestructura de significación que hay detrás del diseño lúdico del videojuego.

\subsubsection{Discurso lúdico del videojuego}

Aunque en los años noventa los videojuegos ya estaban posicionados, la academia no los había estudiado. Solo en 1997, aparecen dos investigaciones sobre el videojuego como texto 
y narración, uno Cybertext: perspectives on ergodic literatura, de Espen Aarseth (1997), y The future of narrative in cyberspace, de Janet Murray (1998). En 2001, se publican varias investigaciones sobre el videojuego, como la revista Game Studies, en el Departamento de Estética Digital de la Universidad IT de Copenhague. Esto coincide con la aparición de un gran número de videojuegos que invaden el mercado.

Pérez (2011) plantea los siguientes aspectos como ejes de la estructura del videojuego: Sujetoentorno; Mundo-experiencia; Experienciaobjetivo; Redundancia-variabilidad.

Sujeto/entorno: Margaret Mead -citado por Pérez (2011)- destacó que una cualidad del juego es que, para tener éxito, el jugador necesita integrarse en una estructura ajena, representada por las reglas del entorno del juego.

Mundo/experiencia: La experiencia está condicionada por las reglas del videojuego, de modo que el jugador hace lo que el videojuego quiere que haga.

Experiencia/objetivo: el videojugador aprende a distinguir entre la conducta que debe seguir para alcanzar el triunfo y la que lo lleva al fracaso.

Redundancia/variabilidad: Roger Caillois (citado por Pérez, 2011) propuso una famosa distinción entre dos géneros del juego: El juego ludus, rígido y el juego paideia, libre.

\subsubsection{Estructura del diseño del videojuego como lenguaje}

Para realizar este análisis se tuvieron en cuenta los principales referentes de la microestructura del videojuego: sujeto, entorno y experiencia.

Sujeto/jugador: el jugador es una dimensión descriptiva, que consiste en las reglas de estado, como el número de vidas, el estado de salud, el estado de ánimo, etc. y otra de acción/transformación, que consiste en los modos de hacer, como las variaciones en cada nivel.

Reglas de competencias sujeto/jugador: las reglas del juego han sido predeterminadas para que respondan a los objetivos planteados en una selección cultural. Pérez (2011) cita a
Greimas y Courtés sobre su clásica tipología semiótica respecto a las modalidades básicas de querer/deber y de saber/poder, adaptadas al videojuego. Según la relación poder/saber, se clasifican los juegos.

Reglas transformacionales del sujeto/ jugador: definen cómo se desarrollan las acciones en el videojuego que se han establecido mediante dos tipos: Reglas de actualización: definen una acción en el videojuego. El jugador solicita una acción del sistema de juego y esta se activa; Reglas de realización: definen el vínculo de una acción con un resultado.

\subsection{Los valores sociales y los videojuegos}

La contradicción expresada arriba entre los autores que resaltan las potencialidades didácticas de los videojuegos y los que ven en ellos un peligro por los valores negativos que exhiben requiere observar en detalle las diferencias de los conceptos de "usos" y "apropiaciones". Esta aporía proviene de la teoría de "usos y "gratificaciones" de Elihu Katz y Jay Blumler (1974) en los años setenta del siglo pasado, frente a la teoría de los efectos de los medios. Por esto, aquí se aborda la recepción más que el diseño y la producción de los videojuegos.

Esa percepción de insuficiencia la comparten investigaciones que tratan sobre objetos que interactúan en el nuevo ecosistema comunicativo de la tecnología digital. La teoría de los efectos, los análisis del discurso, la metáfora de la aguja hipodérmica, la teoría de las mediaciones y la teoría de usos y gratificaciones, puesto que surgieron respecto a la comunicación masiva, tienen un poder explicativo limitado para comprender fenómenos comunicativos como los videojuegos (Acosta-Silva \& Muñoz, 2012).

La noción de "uso" fue compartida por varias teorías de la comunicación, pues los medios se usan para satisfacer una necesidad: informarse, divertirse, contextualizarse, "ponerse a tono", buscar modelos de conducta, asomarse a la intimidad de las personalidades públicas... Pero un videojuego no se usa, como no se usa un partido de fútbol o un juego de rol, sino que propician una experiencia de 
apropiación, como sucede con los videojuegos. De aquí proviene la propuesta en esta investigación de la apropiación como categoría.

El concepto de "apropiación" se basa en Katz y Blumler (1974) sobre la "gratificación", y en Latinoamérica en las teorías de OrozcoGómez (2001), Martín-Barbero (2006) y Winocur (2006), pues el advenimiento de Internet implica la "apropiación" como un emergente proceso de recepción. Entonces, es preciso preguntarse por qué se vinculan de manera taxativa las apropiaciones que suscitan los videojuegos con su dimensión axiológica.

La primera razón es que todo proceso de apropiación en un proceso comunicativo -y los videojuegos lo son, aunque de una índole muy distinta a la de los medios masivos- tiene una dimensión axiológica. La segunda razón es que toda práctica lúdica tiene como meta el desarrollo de determinados valores, entre los que se resaltan los valores sociales y los procesos de socialización (Caputo \& Gamallo, 2010). Y la tercera razón es que este estudio aborda el grupo poblacional de los preadolescentes, que es crucial para las políticas públicas que buscan la formación de ciudadanos bajo principios democráticos de determinados valores, como una estrategia para superar la violencia y la guerra.

La educomunicación ha concluido que la institución escolar debe transformarse al reconocer que las tecnologías de la información y la comunicación modifican los procesos de conocimiento. Por eso, el sentido del cambio de los videojuegos en el aprendizaje y la formación de los valores sociales implica saber cuáles son los retos que enfrentan los espacios y los dispositivos educativos tradicionales, y la relación de las nuevas competencias comunicativas promovidas por las redes virtuales sobre las competencias ciudadanas.

Esta relación se da en un escenario de tensiones entre la escuela y los videojuegos. Cada desarrollo tecnológico de los medios de comunicación interpela la institución escolar. Como en su momento sucedió con la televisión -Ferrés (1988), (1994) y Pérez-Tornero (1994)-. Afinales de la década de los ochenta yenla década de los noventa, los estudios de comunicación y de educación abrieron un campo en el que uno de sus resultados más sobresaliente fue zanjar las inútiles dicotomías de escuela/televisión y aprendizaje/entretenimiento. Como lo expresa Victoria Camps (1994) en la presentación del libro de Pérez-Tornero citado:

Estamos hartos de oír que lo que se hace en la escuela o en la familia lo deshace, en un momento, la televisión. Sospechamos que la televisión es un medio desaprovechado: que sus posibilidades para enseñar e influir positivamente, sobre todo en la infancia, son extraordinarias (Camps, 1994, p. 15).

La escuela "aprendió" de ese distanciamiento de la televisión, que ahora su supervivencia como institución depende de su actualización respecto de los nuevos dispositivos de producción, almacenamiento y distribución de la información y que estos procesos modifican de muchas maneras la producción de conocimiento. Ese aprendizaje fue fácil para la escuela respecto al aprovechamiento de los computadores -desde finales de los años ochenta- y de internet -a partir de 1993- No obstante, no sucedió lo mismo con los videojuegos.

\subsubsection{El lenguaje digital y los valores sociales}

Estos planteamientos interpelan la escuela como el espacio necesario donde se desarrollan competencias comunicativas que guardan relación con las competencias ciudadanas. Como lo plantea Carlos Valderrama (2010), la formación en competencias ciudadanas y el aprendizaje de la democracia van mucho más allá del gobierno escolar que suele replicar un sistema representativo en crisis, y ve en las formas organizativas que proporciona internet una oportunidad para la formación política: "En el terreno político una de las características de las esferas públicas virtuales es su organización a manera de red" (p. 296). El entorno digital exige del ciudadano el acceso a la información a través de Internet, y también su participación mediante la producción de contenido y la iniciativa de los intercambios comunicativos.

Pareciera que estos planteamientos inclinan la balanza hacia una postura que 
asume los videojuegos como una práctica que favorece sin fisuras el desarrollo de los valores sociales. No obstante, la tensión entre la escuela y los videojuegos sobre la formación de valores sociales no debe restringirse al aspecto de los contenidos, pues ese terreno es estéril (AuberniSerra, 2007).

El planteamiento que emergió en la investigación -que por supuesto no se reclama como inédito- es que hay un nuevo entorno de aprendizaje, estructurado por la alfabetidad digital que acelera la obsolescencia del entorno del aprendizaje tradicional y es cercano a las competencias ciudadanas. Se han escogido algunas competencias formuladas por Aparici (2010) relacionadas con el concepto de alfabetidad digital. Son competencias comunicativas de autonomía, libertad, creatividad, participación, crítica y reconocimiento del otro: Capacidad para interpretar y darle sentido a la información en función de la elección de un itinerario de navegación; capacidad de realizar una búsqueda con criterio definido; capacidad de descubrir la arquitectura de la información y las posibilidades de participación de los interactuantes; Capacidad de comprender el sentido de la participación en la web y en la telefonía móvil; capacidad de analizar identidades de personas, sitios, plataformas; capacidad de separar la información importante de la superflua; Capacidad de detectar los intereses y las intenciones de quien elaboró la información; capacidad de descubrir quiénes están representados en la información; capacidad de analizar el modelo comunicativo y pedagógico de entornos virtuales.

\subsection{El Grand Theft Auto V}

Para los estudiantes participantes, los videojuegos preferidos son Fifa, Call of Duty y Grand Theft Auto V (GTA V). Este último representa al niño terrible de los videojuegos, que actúa en la ciudad del videojuego, inspirado en el cine de gánsteres de Tarantino. Fue creado en 1996 por un grupo de jóvenes conocidos como DMA Design y después como Rockstar Northe.
Es un videojuego cuyo eje narrativo se da sobre la historia de un grupo de delincuentes que, en la imaginada cuidad de Los Santos, deben realizar una serie de misiones con actos delictivos como asesinatos, torturas, robos a bancos y robos de autos. La primera aparición con una expansión a Nintendo fue en 1999 y dio origen a múltiples versiones por su acogida mundial (aparece en 3D en 2001 y en 4D en 2009).

El juego más vendido de Play Station 2 fue Grand Theft Auto San Andreas, iniciador de esta saga de la cual analizamos su quinta versión que se lanza al tiempo con Play Station 4. Va dirigido a mayores de 18 años, pero quienes lo juegan son los niños y las niñas. Se vende libremente en cualquier almacén de videojuegos.

\subsubsection{Sinopsis del Grand Theft Auto V}

Michel Towley aparece después de nueve años, tras haber sido dado por muerto en un atraco frustrado en Lundenforff (North Yankton). Es puesto bajo protección de testigos por un agente corrupto del FBI, Dave Norton, con quien establece una amistad. Gracias a esto viaja con una nueva identidad "Michel De Santa" junto con su familia, a Los Santos (San Andreas).

Franklin Clinton es otro personaje de la historia que aparece cuando se le pide el favor de recuperar el auto del hijo de Michel, parte de su trabajo es ser embargador en un concesionario.

Cuando Michel conoce lo que está sucediendo, decide esconderse en el auto para proteger a su hijo y se enfrenta a Franklin, a quien obliga a chocarse contra el concesionario, por lo cual es despedido, y a partir de ese momento se vuelven amigos.

Más adelante, Michel descubre a su esposa, Amanda, acostada con su entrenador, entonces él y Franklin lo persiguen hasta una mansión que resulta ser propiedad de la amante del narcotraficante mexicano Martin Madrazo. Madrazo encuentra a De Santa y le exige pagarle por los daños. Michel le paga con el dinero que obtuvo en un robo a la cadena de joyerías Vangelico. Trevor Philips, compañero de robos en Lunderfoff se entera del atraco por 
la televisión y al reconocer a su excompañero como autor del hecho, emprende la búsqueda hasta encontrarlo.

La vida personal de todos los personajes comienza a complicarse, Michel realiza actos imprudentes que afectan a su familia. Trevor se siente traicionado al saber que su compañero, que creía en prisión, está muerto y enterrado y así se van desarrollando las historias.

La mecánica del juego es disparar y cubrirse lo que invita al videojugador a reconocer y acomodarse en el espacio y adoptar los movimientos y las características de su personaje.

Este juego permitió la confrontación entre los "valores" intrínsecos al videojuego y los valores vistos en la práctica cotidiana de los jóvenes partícipes en la investigación.

\section{Metodología}

El carácter de este proyecto es cualitativo con la utilización de herramientas etnográficas -grupos focales, entrevistas semiestructurada, observación directa-. Además, se recurrió a herramientas de otro orden metodológico que permitieron manejo estadístico -cuestionario tipo Likert- con el fin de obtener información complementaria que permitiera una mayor precisión en el análisis y los resultados (Guber, 2005).

El propósito de esta triangulación fue mitigar los problemas de sesgo (Blaikie, 1991). En el informe de los resultados de la investigación, se sigue el orden de los hallazgos de cada una de las herramientas, que se relacionan para la comprensión de los datos obtenidos, reduciendo las inclinaciones de análisis de los datos recolectados, en un área de difícil concreción como es la apropiación de valores sociales y su correlación con los videojuegos, en especial con aquellos cuyas estructuras narrativas y la caracterización de los personajes se dan en ámbitos de violencia y criminalidad, como es el Grand Theft Auto V.

Con estas herramientas, se buscó comprobar las tendencias detectadas en una misma unidad de observación: los estudiantes de grado séptimo, grupo 703, del colegio Santo Tomás de Aquino, de Bogotá, con quienes se indagó la relación entre el uso de videojuegos colaborativos en redes sociales y la formación de valores sociales (tolerancia, respeto, solidaridad, alteridad) en pre-adolescentes.

Esta postura metodológica, que incluye la etnografía virtual (Hine, 2004) nos permitió participar en los contextos que indagamos, y establecer vínculos con los procesos y los sujetos vinculados, con una postura dialógica y abierta a reconocer como válidos los conocimientos, saberes y creencias, en conjugación con otras herramientas que permitieran aumentar la validez de los hallazgos.

\section{Hallazgos}

Pese a que en el informe de la investigación se presentaron en detalle los resultados parciales de cada herramienta, en función de la brevedad que exige un artículo, se relacionan a continuación las síntesis de los grupos focales, de las entrevistas y de la encuesta.

\subsection{Los grupos focales}

Los hallazgos expresan el ejercicio desarrollado en dos subgrupos, uno de $10 \mathrm{y}$ otro de 9 estudiantes, que conversaron sobre las mismas preguntas. Los resultados se estructuran en la investigación según los bloques temáticos: preguntas de apertura, preguntas introductorias, preguntas clave y preguntas de cierre. Aquí, solo se presentan los resultados de las preguntas clave y las preguntas de cierre.

\subsubsection{Preguntas clave}

De las posibilidades que ofrece el juego como las rutas, la posibilidad de robar un auto, robar peatones o realizar sobornos, ¿cuál es la más atractiva y por qué? / De las misiones de delincuencia, ¿cuál es la más más interesante y por qué? / Y ¿qué pueden decirnos de las misiones alternativas, los juegos pasivos?: ¿cuál les gusta más y cuál menos y por qué?

Todos los participantes, en ambos grupos focales, coinciden en que la atracción del juego no se basa en las posibilidades de robar, torturar o asesinar, sino en los retos para adquirir destrezas y cumplir las misiones y 
porque las historias les parecen divertidas y son "chistosas".

Algunos se sienten atraídos por hacer acrobacias con los carros. Esto está asociado con destrezas en la manipulación de los controles. Las formas de "jugador pasivo" no son atractivas, aunque algunos dicen que las juegan cuando "están aburridos" o "por hacer algo diferente".

Sobre la opción de jugar sin violencia, piensan que es mejor acudir a otros videojuegos, como Fifa, que juegan con regularidad. Dicen que es mejor ser narco que ser taxista, pizzero o recolector de basura, porque así no hay emoción ni se logra conseguir dinero.

Les gustan las misiones que impliquen mayores dificultades. Algunos aluden al uso de claves y de recursos externos para obtener mejores logros (widgets), pero la mayoría rechaza esta opción, a la que consideran como "una falta de respeto" con las reglas del juego.

¿Hay alguna misión o parte del juego que sus papás les hayan prohibido jugar? ¿qué les dicen sus padres? y ¿qué piensan ustedes de una prohibición?

Los papás son quienes compran los juegos, y ninguno se inquieta por sus temas. Los padres suelen jugar con ellos. Son las abuelas quienes les expresan inconformidad por estos juegos. Los papás los invitan a concentrarse en jugar las misiones. Les han llamado la atención sobre los burdeles y el empleo de "malas palabras". A veces, les reducen el tiempo de juego para que hagan las tareas escolares o alguna otra actividad.

¿Alguno de ustedes ha dejado de realizar una misión porque considera que es incorrecta o en el juego todo está permitido?

Mientras se está jugando, todo está permitido. El juego se trata de cumplir las misiones y no importa si uno mata al amigo "eso es normal". Piensan que es diferente cuando uno está jugando a cuando está actuando en la vida real. Varios manifiestan rechazo por situaciones como ir a burdeles, meterse con mujeres, consumir drogas y alcohol. A veces hay "mucho vicio": se rechaza este aspecto del juego.

Es normal matar gente para cumplir las misiones; sin embargo, rechazan la tortura y los excesos de Trevor, porque le gusta torturar. Las misiones solo se dejan cuando son difíciles de superar. El abandono transitorio de una misión depende de las destrezas necesarias para ganar.

\subsubsection{Preguntas de cierre}

¿Qué es lo más importante que ustedes han aprendido en este juego? / ¿Cuáles son los aspectos positivos y los aspectos negativos que ustedes encuentran en el juego?

Se correlaciona el mundo del videojuego y el mundo real, y se encuentra que no son tan diferentes y se debe tener cuidado: se aprende a conocer la realidad, a tener cuidado y a ser escéptico. También se dan elementos de control: "Si uno roba en el juego, lo persiguen durante un tiempo; pero si uno roba en la vida real, lo persiguen para siempre"; en el juego, "si uno muere, reinicia nuevamente; en la vida real, no"; el juego "es un escape a la realidad, en la vida real uno no puede hacer eso; "el juego es como una vida alternativa"; "hay que ser muy cuidadoso con lo que se aprende y lo que se ve en el juego"; "no debe traerse a la vida real"; "me muestra lo que no debo hacer en la vida real".

Se expresan algunas reservas: "hay que tener cuidado, porque mientras uno está disfrutando, todo eso penetra en el subconsciente"; "uno aprende a contestar mal, a decir groserías y hasta de pronto a responder con golpes cuando lo molestan"; "mientras se juega, se produce un gran estrés"; "cuando se juega on-line, no se puede parar".

\subsection{Entrevistas}

Se hicieron entrevistas a diez estudiantes. Los resultados se presentan siguiendo el mismo esquema de indagación en el que se realizó la actividad.

\subsubsection{Acerca de los personajes}

Franklin: es el personaje que más atrae a los participantes. No le tiene miedo a nada; lo respetan por sus trabajos; tiene la mejor casa, los mejores carros y buenos contactos. Es favorito por su forma de actuar, por su personalidad, 
por el poder, porque los demás hacen lo que él quiere, porque logró "superarse".

Michael: Es un personaje "neutro" en aceptación. Se le reprocha que "siempre ha sido rico"; "Es millonario, no necesita la plata sino que todo lo hace por diversión". Esto contrasta con el esfuerzo y la superación de Franklin. Hacen referencias a la condición "catastrófica" de su familia. Les admira su control, a pesar de las dificultades con los hijos y con la esposa.

Trevor: despierta mayor rechazo: "Es muy loco", "no se sabe controlar y no le interesa el futuro"; "es un sociópata". Consideran que es muy agresivo y grosero, mata y golpea a las mujeres. Trevor defeca en sitios públicos, es distante y no socializa con la gente. Se "salta" la misión: le falta seriedad en las misiones y no sigue las reglas". Despierta admiración la jugabilidad del personaje.

\subsubsection{Acerca de los valores de respeto, tolerancia y otredad}

El respeto: se formula respecto a la convergencia entre lo real y lo virtual. Todos los participantes se apropiaron del respeto en su concepción y su aplicabilidad. Es ser igual al otro, respetar su opinión y su forma de pensar; es convivir, ser amigos, ayudarse; en la vida real, saber que los otros tienen los mismos derechos y deberes y asumir que los otros son diferentes; es "ayudar, más que felicitar"; es "respetar la opinión y no ofender"; es saber valorar a otros y saber que los otros son diferentes; es aprender a valorar las diferencias, el color, "saber que no hay que agredir ni insultar"; es el buen trato hacia los demás.

En algunas respuestas, el respeto no responde al reconocimiento de los otros, sino a una asociación con el temor hacia los más fuertes: "hay que saber a quién se tiene al frente"; respeto hacia los grandes (personas mayores), porque saben más, no hay que tratarlos como si fueran iguales; respeto a los compañeros porque son más grandes.

Respecto a cómo se lleva a la práctica el respecto, expresan: "Se debe respetar para que lo respeten"; "en el colegio, respetamos ayudando y protegiendo"; "dialogando"; "no discriminando"; darse con los otros "por igual"; "me respetan cuando hablamos en buen tono: nos respetamos mutuamente"; "es importante el autocontrol, como forma de respetarse a sí mismo". Estas fueron dos menciones sobre el respeto a sí mismos y no solo como "dadores".

Se respeta a quienes están cerca, no a los extraños. Este es un aspecto relevante por su vinculación con los valores de solidaridad, alteridad y tolerancia.

Consultados por los espacios y los contextos en que se aprende sobre el respeto, la referencia fue siempre el grupo familiar: desde pequeños, los papás les "enseñan cosas que no deben hacerse"; "a lo bien los papás, deben conservarse".

En el juego, el respeto es relacionado con el temor y es de socios, para las misiones. No se da por separado. Aun así, se perciben relaciones de amistad: "Ellos (Franklin, Michael Y Trevor) muchas veces son amigos y se apoyan no solo para las misiones". Sin embargo, al final, ellos (Franklin y Michael) deben matar a Trevor y lo hacen.

Los chicos reflexionan sobre la relación de respeto en las familias del videojuego y las contrastan con sus familias reales, en un juicio negativo sobre las del juego. Algunos jóvenes reflexionan sobre la relación miedo/respeto $\mathrm{y}$ dicen que "cuando hay miedo, deja de haber respeto". Se censura el adulterio y las acciones que de este se derivan: "Está bien que maten al amante, porque ella lo irrespeta, pero en el juego; en la vida real, no". "Sería mejor terminar la relación, aunque algunos las golpeen o al man". "no hay que tener amantes cuando se está casado, porque es irrespeto. Pero no hay que matar o agredirse. Lo mejor es alejarse". "La infidelidad es irrespeto, por los compromisos que se adquirieron cuando se casaron".

$\mathrm{Se}$ reconoce una diferencia entre las conductas y los alcances de la vida real y del mundo virtual, cuyo sustento es su conciencia y las posibilidades diferenciadas de los espacios: "Lo que hace interesante el juego es la posibilidad de hacer algo que no puede hacerse en la vida real"; "El juego lo permite por las habilidades, pero también por normas y leyes"; "En la vida real, no hacemos lo mismo que en el juego". 
La solidaridad: La aproximación al valor solidaridad se dio en torno a su expresión en la vida social, y en las relaciones entre los personajes. Sobre ella se obtuvieron expresiones que indican una apropiación conceptual, ligada a dar a los demás, cuando tienen necesidad. En el juego, la solidaridad es entre personajes que se reconocen como parte de un mismo grupo: "solidaridad es dar lo que tú puedas para ayudar"; "Es ser buena persona"; "Lo que estoy dispuesto a hacer por alguien más"; "Dar a los más necesitados, sin esperar nada a cambio"; "si fuéramos solidarios, no existirían los conflictos. Pero la gente piensa solo en ellos".

En el juego, la solidaridad se entiende en términos de colaboración para cumplir las misiones: La solidaridad está limitada a las misiones, para salvarse de problemas, para los logros en las misiones difíciles, para robar un banco: "hacer grupo para cumplir la misión"; "Se da por interés, para conseguir más plata"; "El juego no está configurado para la solidaridad..."; "Franklin, Michael y Trevor son socios. Sus relaciones se dan solo allí: los tres buscan un mismo fin"; "Hay pocas relaciones de amistad verdaderas"; "En el juego, solo es por dinero, que es una clase de solidaridad, es un intercambio".

Jugar en la modalidad de multijugador en línea se da para aprender de los demás, para divertirse o para ser reconocido por las destrezas y las habilidades. Los jóvenes que participaron en la investigación coinciden en jugar solo para divertirse. Las percepciones sobre quienes juegan en modo multijugador, señalan:

- Del reconocimiento: algunos son obsesionados, les gusta ser muy buenos y ser reconocidos; el reconocimiento se da por logros y cumplimiento de metas; muchas personas acuden a despertar miedos: compara a estos con Franklin "son peligrosos"; hay algunos que son muy destacados, que juegan por el reconocimiento; prestigio por superación de niveles y experiencia que se tiene o para que otros te reconozcan y sepan tu nombre.

- Actitud en el juego: no vale la pena ser humilde; no tienen beneficios para sí mismos; lo importante es pasar las misiones y ganar; en esta modalidad, no se da respeto ni ayuda; más que respeto o compañerismo, lo que se busca es ganar.

- Los recursos y la jugabilidad: es diferente, porque se ven cosas que en la campaña no; generalmente se siguen las normas: se respeta el juego. Es más importante seguir las normas.

- De los vínculos que se establecen: no hay contactos "por chat" y no se hacen amigos; se juega con diferentes personas; las relaciones que se establecen entre grupos es de ayuda, porque son del mismo gremio: para conseguir dinero; se busca equipo sin conocerse (distinto a otros juegos, en los que sí se arman equipos entre grupos que permanecen consolidados).

\subsubsection{Valoración sobre los aspectos del juego}

En las reflexiones sobre la construcción de valores, se destacan las siguientes apreciaciones: "mientras se está jugando GTA no es como ser buena persona"; "uno "hace" el personaje con el carácter de uno"; hay que tomar conciencia de que el juego no es real y de que no hay que hacer en la vida real lo del juego; GTA es un espejo de la vida real, no debe dejarse llevar de lo que se hace en el juego; Todo depende de la conciencia, del pensamiento y el tipo de persona; Las críticas que se hacen al juego son ciertas: rechazo a las formas de juego súper agresivo; el juego es para mayores de 17; Hay que tomar el juego como un escape de la realidad porque uno puede tener carros lujosos, robar, matar, acumular...; en el juego, todo está permitido, pero no es lo mismo en la "vida real"; jugar GTA no es para establecer lo que uno va a ser en el futuro, no se juega para ser ladrón o asesino; él ya tiene claro qué es bueno y qué es malo, pero hay niños y niñas pequeños que no saben distinguir; Tomar el juego como pasatiempo, no como modelo. En la vida real hay más tolerancia. Por ejemplo, en los videojuegos no hay campañas como "contra el racismo"; en los videojuegos de violencia no hay amistades. Otros videojuegos sí lo permiten; en el videojuego, uno es un muñequito, donde 
no hay leyes ni nada, pero eso no le corresponde a los jóvenes en la vida real: "Cada uno tiene ya sus valores"; "Si uno ha recibido buenas enseñanzas, uno no se comporta en la vida real como en el juego; son diferentes"; "Lo más importante es lo que enseñan en la casa y en los colegios"; "A uno en la casa le enseñan a portarse bien y a respetar a los demás, son los valores que enseñan los padres".

\subsubsection{La encuesta}

El cuestionario pensado como instrumento de control y precisión ofreció 39 sentencias, de las cuales 11 indagaron por el valor tolerancia, 8 por el valor respeto, 12 por el valor alteridad y 9 por el valor solidaridad.

Tolerancia. Ocurre cuando las sentencias proponen la diversidad de opiniones y de culturas y el derecho a expresarlos. Sin embargo, cuando se busca la aplicación de esos valores y al indagar por relaciones homosexuales, tanto en el juego como en la vida cotidiana, la aceptación disminuye. Se consideran los derechos de los demás y se rechaza el atropello del derecho ajeno, incluso sobre personajes de GTA. Hay permisibilidad por la violencia y las prácticas delictivas en la mitad de los encuestados, no sobre el juego sino sobre contextos reales.

El atractivo del videojuego no se da por las posibilidades de la violencia, permitido por su estructura narrativa. Esta es una de sus características, pero no es lo que seduce.

Respeto. Hay un alto grado de apropiación de este valor y una concordancia entre el respeto como actitud y el juicio hacia las relaciones entre los personajes. La mayoría de los estudiantes estima que se deben respetar las personas sin consideración de atributos como las riquezas o el poder. Consideran que si todos se respetaran, se podría vivir en armonía.

Hay respeto por las normas. Cuando estas se extrapolan del juego a la vida cotidiana, pero en algunas circunstancias se debe recurrir a las trampas.

Niegan el miedo como fuente de respeto y no expresan consideraciones de respeto hacia prácticas ilícitas, ni aun cuando estas se dan en relación con el videojuego.

Alteridad. Sobre la vida real, se rechazan la violencia, la tortura, el sometimiento y son sensibles ante el dolor del otro, aun cuando este sea violento o se justifique para alcanzar una meta. Sin embargo, cuando se busca afinidad hacia los demás en el juego, la proximidad disminuye, lo que indica la lectura del otro en la realidad y en el juego. Son sensibles también ante la discriminación por condiciones de sexo, religión y raza.

Solidaridad. La solidaridad es un concepto que debe aplicarse, especialmente entre las personas cercanas, y después hacia los desconocidos. El alcance de la solidaridad disminuye cuando implica un sacrifico. Se destaca el beneficio del grupo sobre el provecho individual.

En el videojuego, las decisiones que los participantes deben tomar sobre las conductas censurables de los personajes, no hay acuerdo al extrapolar las dinámicas del juego y la aplicación de este valor como un acto de solidaridad hacia las personas reales.

\subsection{Triangulación a manera de conclusiones}

Los estudiantes toman las claves (widgets) como formas de hacer trampa y desaprueban este tipo de ayudas, lo cual resalta la importancia que les dan al desafío y al esfuerzo por superar las misiones: mientras más dificultades haya en el juego, el atractivo es mayor.

El atractivo del videojuego son sus posibilidades de jugabilidad, el reto para el desarrollo de habilidades y destrezas, mientras los jugadores y la competencia para alcanzar las metas, se recurra a la violencia. No obstante, las historias que se proponen en el juego, los personajes, las escenas, las secuencias, las formas en que se relacionan son atractivas porque son divertidos.

Se valora el respeto a las reglas del juego, pues el jugador debe jugar según los parámetros de exigencia y los recursos del juego, pero se va más allá de las prácticas sociales del relato, como cuando se censura a Trevor por transgredir las normas sociales y "éticas", hasta llegar al crimen. Se acepta que Trevor mate, porque hace parte del juego, pero no que torture. 
Se rechaza la tortura, aunque este sea un mecanismo del juego. Causar daño a otro de modo directo, que haga evidente el dolor no es admitido. Esta condición prima, incluso, sobre la vida.

Se censura el vocabulario soez, los burdeles y el consumo de drogas y alcohol. Sin embargo, la violencia y el crimen se aceptan como algo normal. Los pesos morales aplicados al juego guardan relación con la mirada a estos aspectos observados en la vida real.

Se rechaza el adulterio y el homosexualismo. El primero, en relación con el valor del respeto. El segundo, aunque en la entrevista se acepta por ser expresión de libre personalidad, en la encuesta se desaprueba.

Se diferencia lo virtual de lo real, que los jóvenes expresan como "la conciencia". Esta señala los límites entre lo que ocurre en un espacio como el virtual que, en el GTA V, implica la realización de actos vandálicos, y la vida real, donde las pautas de conducta y de relación con los demás se cimienta en principios como el respeto y la solidaridad y en la convivencia.

Se valora la superación, que se refleja en la admiración que despierta Franklin, por su ascenso social. La admiración por el progreso personal aumenta cuando se contrasta con las expresiones de desdén de Michael, por haber sido siempre rico.

Diferencian los valores en la realidad y la virtualidad. Así, la solidaridad, el respeto, la alteridad y la tolerancia se definen y se aplican de manera diferente en el entorno del juego a como se entienden en la vida real. Esto se observa en la diferenciación que hacen cuando señalan que "en el juego, el respeto es" o "en la vida real, el respeto es".

La familia es el principal referente de los valores: es el espacio de formación, el espejo donde se miran y donde se aprende por el ejemplo de los padres. Así, el respeto hacia los demás, la solidaridad, la tolerancia y la alteridad se forman en el seno familiar y los aprendizajes allí logrados garantizan que apuestas de violencia y de irrespeto como los que se observan en el videojuego no se reproduzcan en los espacios reales.

Consideran que los videojuegos no tienen un carácter formador ni de enseñanza, sino de divertimento. Sin embargo, se manifiesta que sí hay un aprendizaje y es el de no traspasar el hacer del videojuego al hacer en la vida real.

Hay una tensión entre la traslación de los valores entre el mundo virtual y el mundo real, en ambos sentidos. Así, al tomar una posición sobre un comportamiento que en el juego es normal y esperado, los participantes no aceptan, lo que se reconoce como una vacilación entre reconocer como aceptable una conducta que, aunque es lícita en el juego, resulta contraria a los valores de la vida real. El juego es un mundo de crimen, maldad y los antivalores son la normalidad. Eso mismo sucede en el mundo real: en una sociedad donde el crimen es frecuente, todos terminamos aceptando este fenómeno como normal.

\section{Lista de referencias}

Aarseth, E. J.(1997).Ergodic Literature: Sample Chapter from Cybertext: Perspectives on Ergodic Literature. Recuperado de: http:// www.hf.uib.no/cybertext/Ergodic.html

Acosta-Silva, D. A. \& Muñoz, G. (2012). Juventud Digital: revisión de algunas aseveraciones negativas sobre la relación jóvenes-nuevas tecnologías. Revista Latinoamericana de Ciencias Sociales, Niñez y Juventud, 10 (1), pp. 107-130.

Aguilar, M. (2012). Aprendizaje y Tecnologías de Información y Comunicación: hacia nuevos escenarios educativos. Revista Latinoamericana de Ciencias Sociales, Niñez y Juventud, 10 (2), pp. 801-811.

Aparici, R. (2010). Introducción: La educomunicación más allá del 2.0. En R. Aparici (ed.) Educomunicación: más allá del 2.0. Barcelona: Gedisa.

Auberni-Serra, S. (2007). Convivir en paz: la metodología apreciativa: aproximación a una herramienta para la transformación creativa de la convivencia en centros educativos. Bilbao: Desclée de Brouwer.

Blaikie, N. W. (1991). Una crítica del uso de la triangulación en investigación social cualitativa y cuantificativa. Netherlands: Kluwer Academia Publishers. 
Camps, V. (1994). Prólogo. En J. M. PérezTornero (ed.) El desafío educativo de la televisión: para comprender y usar el medio. Barcelona: Paidós.

Camps, V. (2002). Hacia una inmersión cívica. Barcelona: Universidad Autónoma de Barcelona.

Caputo, M. \& Gamallo, G. (2010). Infancia, desarrollo y conocimiento: los niños y niñas y su socialización. Revista Latinoamericana de Ciencias Sociales, Niñez y Juventud, 8 (2), pp. 849-860.

Ferrés, J. (1988). Cómo integrar el vídeo en la escuela: dimensiones técnica, expresiva y didáctica del vídeo, propuestas para su aplicación a las diversas áreas. Barcelona: Ceac.

Ferrés, J. (1994). Televisión y educación. Barcelona: Paidós.

Freud, S. (1948). Más allá del principio del placer. En F. S. (ed.) Obras completas. Madrid: Biblioteca Nueva.

Gross, K. (1902). El juego como escuela de vida. Berlin: Der ästhetische Genuss Gieben: Ricker.

Guber, R. (2005). La etnografía: método, campo y reflexividad. Bogotá, D. C.: Norma.

Hall, S. (1907). Adolescence. New York: Appleton \& Co.

Hine, C. (2004). Etnografía virtual. Barcelona: UOC.

Huizinga, J. (1998). Homo Ludens. México, D. F.: Fondo de Cultura Económica.

Katz, E. \& Blumler, J. G. (1974). The Uses of Mass Communications: Current Perspectives on Gratification Research. Beverly Hills: Sage.

Martín-Barbero, J. (2006). La educación desde la comunicación. Bogotá, D. C.: Norma.

Mason, B. \& Michel, E. (1945). Theory of Play. New York: Barnes and Company.

Meza-Maya, C. V.; Lobo-Ojeda, S. M. \& Uscátegui-Maldonado, J. A. (2014). Usos y Apropiaciones de las Redes Sociales-caso Club Penguin. Bogotá, D. C.: Universidad Santo Tomás.

Murray, J. H. (1998). Hamlet on the Holodeck: The Future of Narrative in Cyberspace. Massachusetts: MIT Press.
Orozco-Gómez, G. (2001). Audiencias, televisión y educación: una deconstrucción pedagógica de la 'televidencia' y sus mediaciones. Revista Iberoamericana de Educación, 27, pp. 155-175.

Pérez-Tornero, J.M.(1994).Eldesafio educativo de la televisión: para comprender y usar el medio. Barcelona: Paidós.

Pérez, O. (2011). El lenguaje Videolúdico. Análisis de la significación del videojuego. Barcelona: Laertes S. A.

Piaget, J. (1961). La formación del símbolo en el niño. México, D. F.: Fondo de Cultura Económica.

Revuelta, F. \& Pedrera, I. (2012). Los videojuegos en red social: definición, modelo de negocio, características y modelo de aplicación en el aula. En F. Revuelta \& G. Esnaloa (eds.) Videojuegos en redes sociales: perspectiva del edutainment y la pedagog. Barcelona: Leartes S. A.

Sedeño, A. M. (2002). El componente visual del videojuego como herramienta educativa. OEI-Revista Iberoamericana de Educación, (9), pp. 3-18. Recuperado de: https://www.google.com.co/?gws_rd=ssl\# $\mathrm{q}=$ ana + mar $\% \mathrm{C} 3 \% \mathrm{ADa}+$ sede $\% \mathrm{C} \overline{3} \% \mathrm{~B} 1 \mathrm{o}+$ $\mathrm{El}+$ componente+visual + del + videojuego $+\mathrm{c}$ omo+herramienta+educativa.

Spencer, H. (1969). Social statics, statics, or the conditions essential to human happiness specified and the first of them developed. New York: Augustus M. Kelley.

Valderrama, C. (2010). Ciudadanía y formación ciudadana en la sociedad de la información. Una aproximación desde la comunicación-educación. En R. Aparici (ed.) Educomunicación: más allá del 2.0. Barcelona: Gedisa.

Vygotsky, L. (1978). Pensamiento y lenguaje. Madrid: Paidós.

Winnicott, D. W. (1982). Realidad y juego. Barcelona: Gedisa.

Winocur, R. (2006). Procesos de socialización y formas de sociabilidad de los jóvenes universitarios en la red. En G. Sunkel (ed.) El consumo cultural en América Latina. Bogotá, D. C.: Convenio Andrés Bello. 